DOI: https://dx.doi.org/10.33289/IJRPC.10.1.2020.10(6)

\title{
METHOD DEVELOPMENT AND VALIDATION FOR THE SIMULTANEOUS ESTIMATION OF IN ATORVASTATIN AND FENOFIBRATE BULK AND PHARMACEUTICAL DOSAGE FORM BY USING RP-HPLC METHOD
}

\author{
Sanjay Kumar ${ }^{*}$, Darsh Gautam ${ }^{2}$ and Poonam Talwan ${ }^{2}$ \\ ${ }^{1}$ Gautam College of Pharmacy Hamirpur, \\ Himachal Pradesh, India. \\ ${ }^{2}$ Himachal Institute of Pharmaceutical Education and \\ Research, Hamirpur, Himachal Pradesh, India.
}

\begin{abstract}
A simple, accurate, economical and reproducible reverse phase high performance liquid chromatographic (RP-HPLC) method was developed and validated for the determination of Atorvastatin and Fenofibrate in bulk and pharmaceutical formulations. The separation was achieved on a Thermo Scientific BDS C18 column $(250 \times 4.6 \mathrm{~mm}$ i.d $5 \mathrm{~m})$ using a mixture of 25mMSodium acetate (pH adjusted to 5.0 With $1.0 \mathrm{M}$ Glacial acetic acid): Acetonitraile (10::90 \% $\mathrm{v} / \mathrm{v}$ )as mobile phase in an isocratic elution mode, at a flow rate of $1 \mathrm{ml} / \mathrm{min}$. The detection was monitored at $254 \mathrm{~nm}$. The retention time of Atorvastatin and Fenofibrate was found to be around $2.672 \pm 0.05 \mathrm{~min}$ (Atorvastatin) $4.971 \pm 0.07 \mathrm{~min}$ (Fenofibrate) respectively. Excellent linearity range was found between $1-5 \mu \mathrm{g} / \mathrm{ml}$ for Atorvastatin and $1-5 \mu \mathrm{g} / \mathrm{ml}$ for Fenofibrate. The method was validated with respect to linearity, robustness, precision and accuracy and was successfully applied for the simultaneous determination of Atorvastatin and Fenofibrate from the combined dosage formulation.
\end{abstract}

\section{INTRODUCTION}

Atorvastatin

(ATOR)

is

chemically7[2(4fluorophenyl)3phenyl4(phenylc arbamoyl)-5-(propan-2-yl)-1H-pyrrol-1-yl]-3,5dihydroxyheptanoate. Atorvastatin is a HMGCOA reductase inhibiter actas anti- hyper lipidemic drug clinically effective drug in the treatment of Hyper cholestrimia . It issoluble in methanol, ethanol, and acetonitrile. Practically insoluble in water. Fenofibrate (FENO),propan2-yl2-\{4-[(4-

chlorophennyl)carbonyl] phenoxy\}-2methyl ropionate is a widely used asAnti-cholesrtimic agent as ppar receptor inhibiter. Atorvastatin and Fenofibrate is available incombined dosage forms as film coated tablets (LIPIKIND). Each tablet contains $10 \mathrm{mg}$ of Atorvastatin and $160 \mathrm{mg}$ of Fenofibrate. It is used for the treatment of Hyper Cholestrimia. For this combination derivative spectroscopic methods and reverse phase liquid chromatographic methods are reported. However, there is no work reported on combination of these drugs by standard addition simultaneous equation method. Hence fast, simple, and accurate and validated spectrophotometric method was developed by standard addition of both drugs by applying simultaneous equation method, the developed method was simple, accurate, precise, specific, sensitive and reproducible which can be efficiently and easily applied to pharmaceutical dosage forms. 
<smiles>CC(C)c1c(C(=O)Nc2ccccc2)c(-c2ccccc2)c(-c2ccc(F)cc2)n1CC[C@@H](O)C[C@@H](O)CC(=O)O</smiles>

Fig. 1: Structure of Atorvastatin<smiles>CC(C)OC(=O)C(C)(C)Oc1ccc(C(=O)c2ccc(Cl)cc2)cc1</smiles>

Fig. 2: Structure of Fenofibrate

\section{Experimental}

\subsection{Apparatus}

A SHIMADZU (Japan) HPLC instrument (LC20AD) equipped with a UV-Visible detector, rheodyne injector with $20 \mu \mathrm{L}$ loop Thermo Scientific BDS C18 column $(250 \times 4.6 \mathrm{~mm}$ i.d $5 \mathrm{~m})$ and LC-Solution software were used. Other instruments included are SHIMADZU electronic balance, BL-220H (SHIMADZU corp., Japan), fast clean ultrasonic cleaner and value 1 stage vaccum pump (model: VE115).

\section{CHEMICALS AND REAGENTS}

All chemicals obtained from local market, Pure Atrovastatin and Fenofibrate were obtained as gift sample from Pharmadeep Remedies Hyderabad

\section{PHARMACEUTICAL FORMULATION}

The tablet dosage form LIPIKIND tablets ( claim: $10 \mathrm{mg}$ Atorvastatin and $160 \mathrm{mg}$ of Fenofibrate) was procured from local market.

\subsection{SELECTION OF WAVELENGTH}

Selectivity of HPLC method that uses UV detector depends on proper selection of wavelength. A wavelength which gives good response for the drugs to be detected is to be selected. From the UV spectra obtained for drugs, $254 \mathrm{~nm}$ was selected as the wavelength for study. Spectra of standard drugs was shown in fig 3.

\subsection{CHROMATOGRAPHIC CONDITIONS}

Chromatographic separation was performed on shimadzu HPLC with Thermo Scientific BDS C18 column $(250 \times 4.6 \mathrm{~mm}$ i.d $5 \mathrm{~m})$ and constant flow pump. Rheodyne injector with 20 $\mu l$ loop. The composition of the mobile phase was in the ratio of $25 \mathrm{mMSodium}$ acetate $(\mathrm{pH}$ adjusted to 5.0 With $1.0 \mathrm{M}$ Glacial acetic acid): Acetonitraile 10:90 \% v/v and was delivered at a flow rate of $1.0 \mathrm{ml} / \mathrm{min}$. The mobile phase was filtered through a $0.45 \mu$ membrane filter and sonicated for $5 \mathrm{~min}$. Analysis was performed at ambient temperature. Chromatogram of standard drugs was shown in fig 4. Optimized chromatographic conditions are listed in table 1.

\subsection{Preparation of Mobile Phase}

The buffer solution of $25 \mathrm{mM}$ of Sodium Acetate was prepared by dissolving $340 \mathrm{mg}$ of dried Sodium Acetate in $100 \mathrm{ml}$ volumetric flask containing $25 \mathrm{ml}$ of HPLC water then shake it until it dissolve. Finally make up the volume with water to $100 \mathrm{ml}$. It gives $25 \mathrm{mM}$. Sodium acetate buffer solution $\mathrm{PH} 5.0$ was adjusted with Glacial Acetic The buffer and acetonitrile were mixed in the ratio of 10:90 $\mathrm{v} / \mathrm{v}$.

\subsection{Preparation of standard Atorvastatin and Atorvastatin, solutions}

Stock solutions were prepared by dissolving $10 \mathrm{mg}$ of Atorvastatin, $10 \mathrm{mg}$ of Fenofibrate in $10 \mathrm{ml}$ of Acetonitrile separately. Aliquots of the standard stock solutions $1 \mathrm{ml}$ of Atorvastatin and Fenofibrate were transferred into $25 \mathrm{ml}$ volumetric flasks and solution was made up to the volume to yield required concentrations of Atorvastatin and Fenofibrate., were prepared by suitable dilution of the stock solution with mobile phase

\subsection{Preparation of sample solution}

Twenty LIPIKIND tablets each containing 10 $\mathrm{mg}$ of Atorvastatin and $160 \mathrm{mg}$ of Fenofibrate were weighed, average weight was calculated and powdered. Above weighed powder to add $15 \mathrm{mg}$ of ATOR to made A quantity equivalent to $16 \mathrm{mg}$ of Atorvastatin and $16 \mathrm{mg}$ of Fenofibrate was weighed and transferred into $100 \mathrm{ml}$ volumetric flask. It is extracted with acetonitrile. The volumetric flask was sonicated for 20 minutes to affect the complete dissolution of the drugs and the solution was made up to the volume with Acetonitrile and filtered.. Suitable aliquots of formulation solution were prepared and injected to HPLC to obtain concentration in the linearity range 


\subsection{Analysis of formulation}

The amount of drug present in the pharmaceutical formulation was calculated through peak area by making use of the standard calibration curve (Concentration in $\mu \mathrm{g} / \mathrm{ml}$ on $\mathrm{x}$-axis and peak area on $\mathrm{Y}$-axis) the results were shown in table-2.

\subsection{RESULTS AND DISCUSSIONS}

Once the HPLC method development was over, the method was validated in terms of parameters like linearity, precision, LOD, LOQ, recovery studies etc,. The proposed HPLC method was validated as per ICH guidelines [19].

\subsection{Linearity and Range}

Linearity was established by least squares linear regression analysis of the calibration curve. The calibration curves were linear over the concentration range of 1$5 \mu \mathrm{g} / \mathrm{ml}$ for Atorvastatin and $1-5 \mu \mathrm{g} / \mathrm{ml}$ for Fenofibrtate, Fig. 5-6 and table 2-3. Peak areas were plotted versus respective concentrations and linear regression analysis was performed on the resultant curves

\subsection{Precision}

The precision of the method was ascertained separately from the peak areas obtained by actual determination of three replicates of a fixed amount of drug. The intraday, inter-day and Repeatability variation in the peak areas of the drug solution was calculated in terms of percent RSD and the results are presented in table 4, 5, 6

\subsection{Recovery Studies}

Recovery studies of the drug were carried out for determining accuracy parameter. It was done by mixing known quantity of standard drugs with the analyzed sample formulation and the contents were reanalyzed by the proposed method. This was carried out at 50 and $100 \%$ levels. Results of recovery are shown in Table 7

\subsection{Limit of Detection and Limit of Quantification \\ The limit of Detection (LOD) and limit of Quantification (LOQ) of the developed method were determined by injecting progressively low}

concentrations of the standard solutions using the developed RP-HPLC method. LOD and LOQ were calculated mathematically. The LOD of Atorvastatin and Fenofibrate were found to be $0.155 \mu \mathrm{g} / \mathrm{ml}$ and $0.144 \mu \mathrm{g} / \mathrm{ml}$ respectively.. The. The LOQ of Atorvastatin and Fenofibrate were found to be $0.471 \mu \mathrm{g} / \mathrm{ml}$ and $0.438 \mu \mathrm{g} / \mathrm{ml}$ respectively.

\subsection{System suitability studies}

System suitability parameters like Retention time, number of theoretical plates $(\mathrm{N})$, Tailing factor, resolution (Rs) etc., were studied, and results are given in Table 8

\subsection{Robustness}

The robustness of an analytical procedure is a measure of its capacity to remain unaffected by small, but deliberate variations in method parameters and provides an indication of its reliability during normal usage. Robustness of the method was investigated under a variety of conditions including changes of composition of buffer in the mobile phase and flow rate. \% RSD of assay was calculated for each condition. The degree of reproducibility of the results obtained as a result of small deliberate variations in the method parameters has proven that the method is robust.

\subsection{Ruggedness}

The ruggedness of the method was assessed by comparison of the intra-day and inter-day assay results for Atorvastatin and Fenofibrate that has been performed by two analysts. The $\%$ RSD values for assays performed in the same laboratory by two analysts did not exceed 2 , indicating the ruggedness of the method.

\section{CONCLUSION}

The proposed RP-HPLC for the estimation of the Anti-Hyperlipidamic drugs (Atorvastatin and Fenofibrate) in the pharmaceutical dosage form were simple, reliable, sensitive and selective providing satisfactory accuracy and precision with lower limits of detection and quantification. The recoveries achieved were good by both the methods. The methods can be recommended for routine and quality control analysis of these drugs in the pharmaceutical dosage forms. 


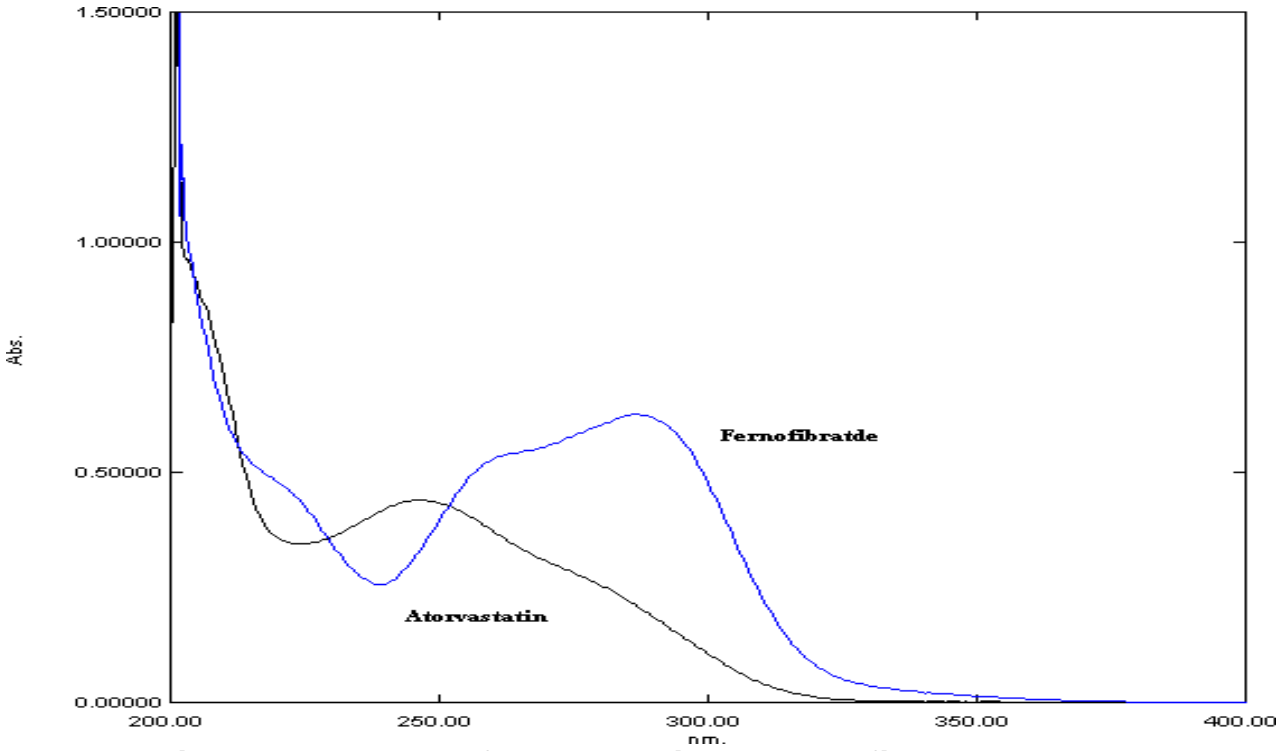

Fig. 3: UV spectra of Atorvastatin and Fenofibrate standards

Table 1: Optimized Chromatographic Conditions

\begin{tabular}{|c|c|}
\hline Parameters & Method \\
\hline Stationary phase (Column) & Thermo Scientific BDS C18 column $(250 \times 4.6 \mathrm{~mm}$ i.d $5 \mathrm{~m})$ \\
\hline Mobile phase & $\begin{array}{l}\text { 25mMSodium acetate (pH adjusted to } 5.0 \text { With } 1.0 \mathrm{M} \text { Glacial } \\
\text { acetic acid): Acetonitraile }(10: 90 \% \mathrm{v} / \mathrm{v})\end{array}$ \\
\hline Flow rate $(\mathrm{ml} / \mathrm{min})$ & 1 \\
\hline Pressure (kgf) & 40 \\
\hline Run time (min) & 10 \\
\hline Column temperature $\left({ }^{0} \mathrm{c}\right)$ & Ambient \\
\hline Detection wavelength (nm) & 254 \\
\hline Drugs Retention time (min) & $2.672 \pm 0.05 \mathrm{~min}$ (Atorvastatin) $4.971 \pm 0.07 \mathrm{~min}$ (Fenofibrate) \\
\hline
\end{tabular}

$m v$

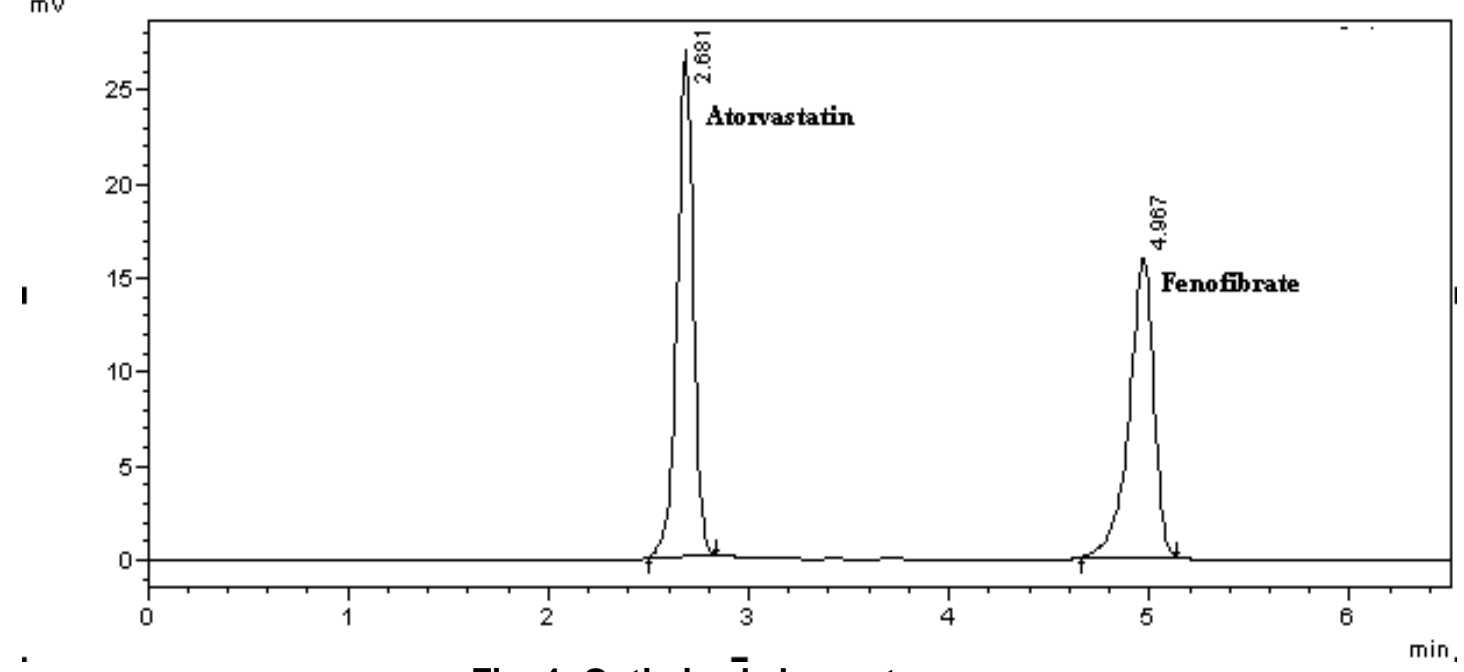

Fig. 4: Optimized chromatogram 
Table 2: Linearity Response

of Atorvastatin

\begin{tabular}{|c|c|c|}
\hline S.NO & Concentration $(\boldsymbol{\mu g} / \mathbf{m l})$ & Peak Area \\
\hline 1 & 0 & 0 \\
\hline 2 & 1 & 53767 \\
\hline 3 & 2 & 99183 \\
\hline 4 & 3 & 151197 \\
\hline 5 & 4 & 195908 \\
\hline 6 & 5 & 241067 \\
\hline
\end{tabular}

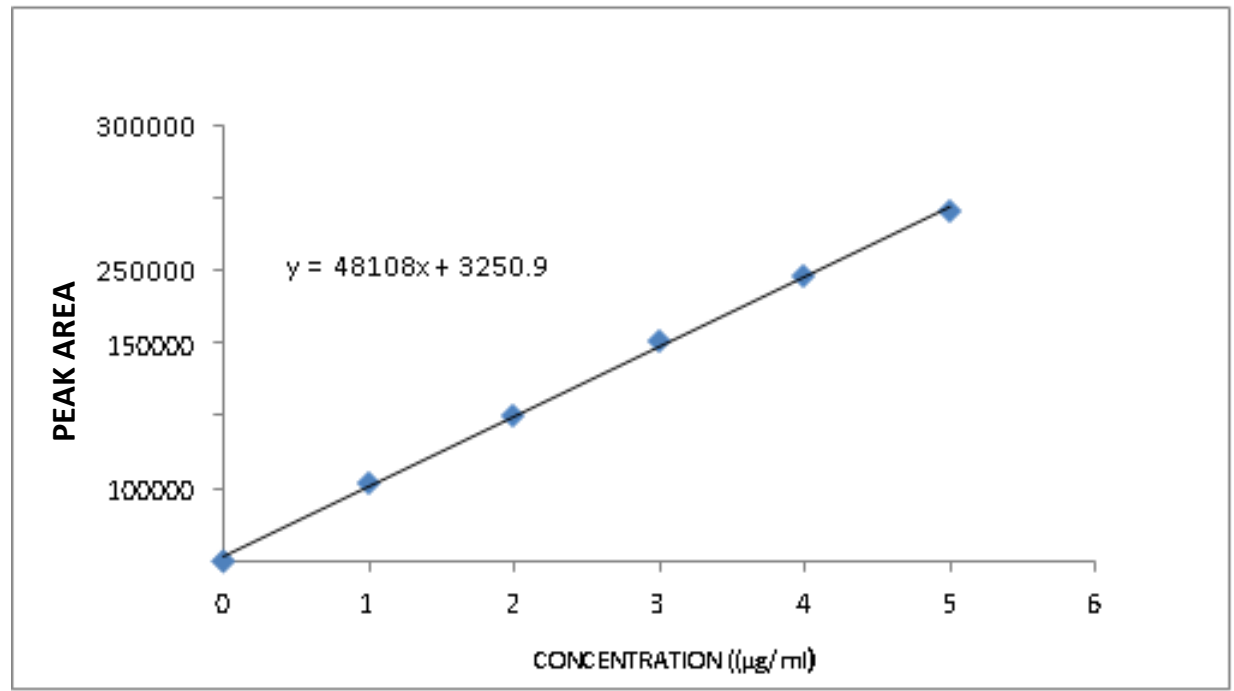

Fig. 5: Calibration Graph of Atorvastatin by RP-HPLC

Table 3: Linearity Response of Fenofibrate

\begin{tabular}{|c|c|c|}
\hline S.NO & Concentration $(\boldsymbol{\mu g} / \mathbf{m l})$ & Absorbance \\
\hline 1 & 0 & 0 \\
\hline 2 & 1 & 47482 \\
\hline 3 & 2 & 89494 \\
\hline 4 & 3 & 135928 \\
\hline 5 & 4 & 181712 \\
\hline 6 & 5 & 221940 \\
\hline
\end{tabular}

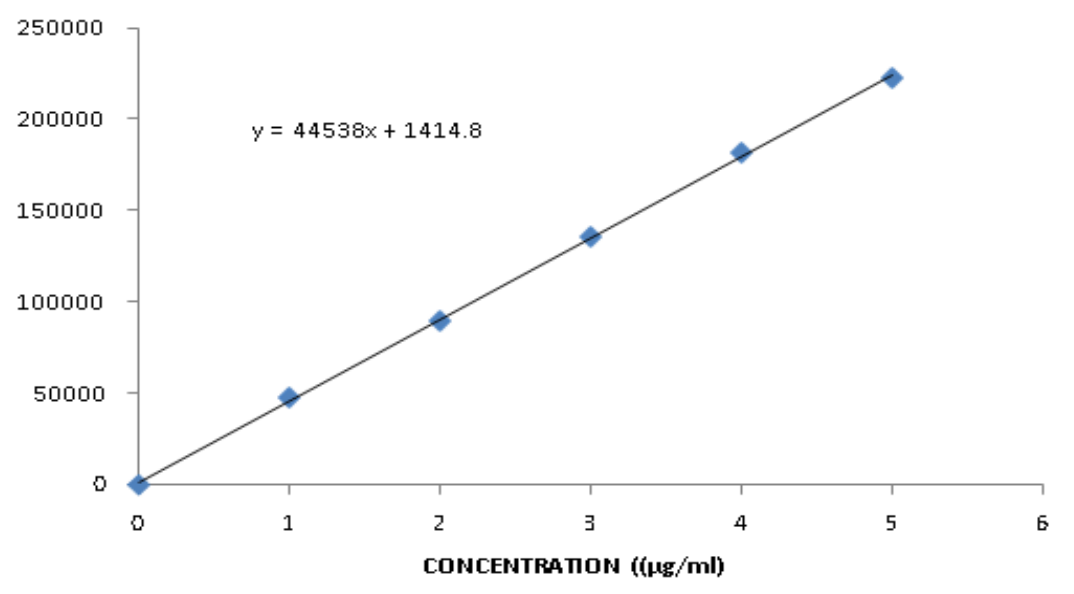

Fig. 6: Calibration Graph of Fenofibrate by RP-HPLC 
Table 4: Intraday Precision

\begin{tabular}{|c|c|c|c|c|c|c|}
\hline \multirow{2}{*}{ S.NO } & \multicolumn{2}{|c|}{$\begin{array}{c}\text { Concentration } \\
((\mu \mathrm{g} / \mathrm{ml})\end{array}$} & \multicolumn{2}{|c|}{ Peak area } & \multicolumn{2}{|c|}{ \%RSD } \\
\hline & ATOR & FENO & ATOR & FENO & ATOR & FENO \\
\hline \multirow{3}{*}{1} & \multirow{3}{*}{2} & \multirow{3}{*}{2} & 99463 & 89201 & \multirow{3}{*}{0.358} & \multirow{3}{*}{0.773} \\
\hline & & & 99615 & 89411 & & \\
\hline & & & 99539 & 89306 & & \\
\hline \multirow{3}{*}{2} & \multirow{3}{*}{3} & \multirow{3}{*}{3} & 151646 & 137488 & \multirow{3}{*}{0.301} & \multirow{3}{*}{0.281} \\
\hline & & & 152713 & 136809 & & \\
\hline & & & 151179 & 137153 & & \\
\hline \multirow[b]{2}{*}{3} & \multirow[b]{2}{*}{4} & \multirow[b]{2}{*}{4} & 193055 & 180855 & \multirow[b]{2}{*}{0.225} & \multirow[b]{2}{*}{0.028} \\
\hline & & & \begin{tabular}{|l|}
195544 \\
195908
\end{tabular} & \begin{tabular}{|l}
181483 \\
181169
\end{tabular} & & \\
\hline
\end{tabular}

ATOR-Atorvastatin- , FENO- Fenofibrate

Table 5: Inter day precision

\begin{tabular}{|c|c|c|c|c|c|c|}
\hline \multirow[b]{2}{*}{ S.NO } & \multicolumn{2}{|c|}{$\begin{array}{c}\text { Concentration } \\
((\mu \mathrm{g} / \mathrm{ml})\end{array}$} & \multicolumn{2}{|c|}{ Peak area } & \multicolumn{2}{|c|}{ \%RSD } \\
\hline & ATOR & FENO & ATOR & FENO & ATOR & FENO \\
\hline \multirow{3}{*}{1} & \multirow{3}{*}{2} & \multirow{3}{*}{2} & 2435983 & 1479796 & \multirow{3}{*}{0.490} & \multirow{3}{*}{0.772} \\
\hline & & & 2459959 & 1457109 & & \\
\hline & & & 2446758 & 1467847 & & \\
\hline \multirow{3}{*}{2} & \multirow{3}{*}{3} & \multirow{3}{*}{3} & 2767646 & 1873240 & \multirow{3}{*}{0.548} & \multirow{3}{*}{0.489} \\
\hline & & & 2797618 & 1879230 & & \\
\hline & & & 2787664 & 1861230 & & \\
\hline \multirow{3}{*}{3} & \multirow{3}{*}{4} & \multirow{3}{*}{4} & 3157395 & 2361278 & \multirow{3}{*}{0.394} & \multirow{3}{*}{0.214} \\
\hline & & & 3157395 & 2351180 & & \\
\hline & & & 3132674 & 2356120 & & \\
\hline
\end{tabular}

ATOR-Atorvastatin- , FENO- Fenofibrate

Table 6 : Repeatability of injection

\begin{tabular}{|c|c|c|c|c|c|c|}
\hline \multicolumn{2}{|c|}{ Concentration $((\mu \mathrm{g} / \mathrm{ml})$} & \multirow{2}{*}{ Injection } & \multicolumn{2}{|c|}{ Peak area } & \multicolumn{2}{|c|}{$\%$ RSD } \\
\hline ATOR & FENO & & ATOR & FENO & ATOR & FENO \\
\hline \multirow{6}{*}{4} & \multirow{6}{*}{4} & 1 & 195908 & 181712 & \multirow{6}{*}{0.419} & \multirow{6}{*}{0.297} \\
\hline & & 2 & 195875 & 180855 & & \\
\hline & & 3 & 195544 & 181483 & & \\
\hline & & 4 & 194299 & 181710 & & \\
\hline & & 5 & 195086 & 180969 & & \\
\hline & & 6 & 19486 & 181169 & & \\
\hline
\end{tabular}

ATOR-Atorvastatin- , FENO- Fenofibrate

Table 7: System suitability studies

\begin{tabular}{|c|c|c|c|}
\hline Drug & $\begin{array}{c}\text { Theoretical } \\
\text { plates }\end{array}$ & Asymmetry & Tailing factor \\
\hline ATOR & 4539 & 1.0 & 0.91 \\
\hline FENO & 7546 & 0.99 & 0.82 \\
\hline
\end{tabular}

ATOR-Atorvastatin- , FENO- Fenofibrate

Table 8: Robustness parameters results

\begin{tabular}{|c|c|c|c|c|c|}
\hline $\begin{array}{l}\text { Chromatographic } \\
\text { conditions }\end{array}$ & Normal & Variation & $\begin{array}{c}\text { Assay } \\
\text { (mean) }\end{array}$ & $\%$ RSD & Fig.no \\
\hline \multirow{2}{*}{ Mobile phase } & \multirow{2}{*}{$10: 90$} & $15: 85$ & 100.1 & 0.89 & \multirow{2}{*}{6.2 .21} \\
\hline & & $20: 80$ & 101.2 & 0.98 & \\
\hline \multirow{2}{*}{ Flow rate } & \multirow{2}{*}{1.0} & 1.2 & 100.5 & 1.51 & \multirow[b]{2}{*}{6.2 .22} \\
\hline & & 0.8 & 100.4 & 1.23 & \\
\hline
\end{tabular}

Table 9: Recovery Studies

\begin{tabular}{|c|c|c|c|c|c|}
\hline Drugs & $\begin{array}{c}\text { Amount taken } \\
(\boldsymbol{\mu g} / \mathbf{m l}) \text { for both } \\
\text { methods }\end{array}$ & $\begin{array}{c}\text { Amount added } \\
(\boldsymbol{\mu g} / \mathbf{m l}) \text { for both } \\
\mathbf{m e t h o d s}\end{array}$ & $\begin{array}{c}\text { Total amount } \\
\text { found }(\boldsymbol{\mu g} / \mathbf{~ m l})\end{array}$ & \%Recovery & $\%{ }^{*}$ RSD \\
\hline ATOR & \multirow{2}{*}{4} & 2 & 1.988 & 99.61 & 0.382 \\
\hline FENO & 4 & 4 & 3.993 & 99.82 & 0.561 \\
\cline { 2 - 6 } & 4 & 2 & 2.012 & 100.60 & 0.256 \\
\cline { 2 - 6 } & & 4 & 4.1 & 102.50 & 0.146 \\
\hline
\end{tabular}


Table 10: Analysis of marketed formulation

\begin{tabular}{|c|c|c|c|c|}
\hline Drugs & $\begin{array}{c}\text { Labelled amount, } \\
\text { mcg/tablet }\end{array}$ & $\begin{array}{c}\text { Amount to be taken , } \\
\text { mcg/tablet }\end{array}$ & $\%$ Label claim & $\%{ }^{*}$ RSD \\
\hline ATOR & 10 & 4 & 99.82 & 0.095 \\
\hline FENO & 160 & 4 & 102.50 & 0.215 \\
\hline
\end{tabular}

\section{REFERENCES}

1. $\mathrm{ICH}, \mathrm{Q} 2$ (R1). Validation of Analytical Procedures. Text and Methodology. 2005.

2. 10) en.wikepedia.org/wiki/Atorvastatin and Fenofibrate.

3. www.drugbank.ca/drugs/DB00709.access ed on 14-9-2014.

4. en.wikipedia.org/wiki/Fenofibrate. accessed on 14-9-2014.

5. www.drugbank.ca/drugs/DB00625. accessed on 14-9-2014

6. Deepan T, Paul A mbethkar K, Viyaya Lakshmi G and Dhanarayu MD. Analytical development and validation of RP HPLC for Estimation of Atorvbastatin and Fenofibrate in bulk tablet dosage forms.

7. Jain $N$, Raghuwanshi $R$ and Deeti Jain. Develoipment and validation of RP- HPLC method for simultaneous Estimation of Atorvbastatin and Fenofibrate in bulk tablet dosage forms.

8. Inamullah Sunil singh, Jyoti rai, Nisha choudhary Surabhi Sharma and Hemendra. Stability indicating absorption ratio Method for Estimation of Atorvastatin calcium and Fenofibrate in tablet dosage form by using UV-spectrophotometer.

9. Dhabale PN and Gharge DS. Simultaneous spetrophotometric
Estimation of Atorvastatin and Fenofibrate in Bulk and dosage form by using simultaneous equation method.

10. Sunil Singh and Rajiv Dahiya. Stabilityindicating rp-hplc method for Estimation of atorvastatin calcium in solid Dosage form.

11. Nakarani, Naresh V, Bhatt, Kashyap K, Patel, Rutva D, Bhatt and Hemaxi S. Estimation of Atorvastatin Calcium and Fenofibrate in Tablets by Derivative Spectrophotometry and Liquid Chromatography.

12. Patel Archita, MaCwana Chhaya, Parmar Vishal and Patel Samir. Simultaneous Determination of Atorvastatin calcium, ezetimibe and Fenofibrate in tablet formulation by HPLC.

13. Kadav AA, Vora DN. Stability indicating UPLC Method fo simultaneous Determination of Atorvastatin and Fenofibrate and their Degradation products in tablets.

14. Bhinge SD, Malipatil SM, Jondhale A, Hirave R and Savali AS. A New Approach to the RP-HPLC Method for Simultaneous Estimation of Atorvastatin Calcium and Fenofibrate in Pharmaceutical Dosage Forms. 